
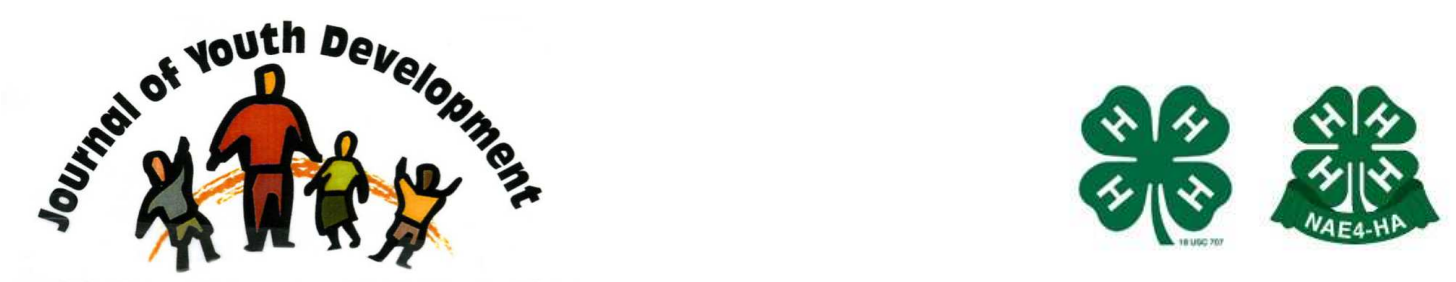

Bridging Research \& Practice

\title{
Scoring On and Off the Field: Examining the Sexual Activity of Adolescent/Emerging Adult Athletes and Non-Athletes Using an Ecological Perspective
}

\author{
Sally Moore \\ Department of School Psychology \\ College of Education \\ University of Florida \\ Gainesville, FL \\ sam0229@ufl.edu \\ Rosemary V. Barnett \\ Department of Family, Youth \& Community Sciences \\ College of Agriculture \& Life Sciences \\ University of Florida \\ Gainesville, FL \\ rbarnet@ufl.edu \\ Mark A. Brennan \\ Agricultural and Extension Education \\ Pennsylvania State University \\ University Park, PA \\ Heather Gibson \\ Department of Tourism, Recreation \& Sport Management \\ College of Health \& Human Performance \\ University of Florida \\ Gainesville, FL
}




\title{
JOURNAL OF YOUTH DEVELOPMENT \\ bridging research and practice

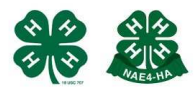

\section{Scoring On and Off the Field: Examining the Sexual Activity of Adolescent/Emerging Adult Athletes and Non-athletes Using an Ecological Perspective}

\author{
Sally Moore, Rosemary V. Barnett, Mark A. Brennan and Heather Gibson
}

\begin{abstract}
This paper highlights a study which used an ecological perspective to explore and identify various risk and protective factors that might influence sexual activity in adolescence and emerging adulthood, with a particular emphasis on the unique experiences of athletes. A sample of 437 undergraduate students completed a questionnaire consisting of the following areas: athletic participation, Athletic Identity Measurement Scale (AIMS), ecological variables, Brief Sensation Seeking Scale (BSSS), sexual activity, and sociodemographics. Results indicate that the link between being an athlete and sexual behavior may not be as direct as previously suggested, but is mediated by the influence of various factors related to the sport participation experience. Factors at the individual, familial, and extrafamilial level were found to affect sexual activity.
\end{abstract}

\section{Introduction}

More than half (56\%) of the adolescents in the United States report playing on at least one school or community sports team (Centers for Disease Control and Prevention, 2005). Many more likely engage in informal or peer organized sports activities. Given that so many adolescents take part in sport, it is important to understand the various ways in which participation may impact participants. Research on the effects of athletic participation has been inconsistent. Some evidence suggests that adolescents who play sports enjoy many positive benefits, including overall positive attitude, enhanced physical and psychological well-being, resistance to addiction, decreased risk for depressive symptoms, increased motivation and engagement in academics, and adoption of a healthy lifestyle (Boone \& Leadbetter, 2006; Hawkins \& Mulkey, 2005; Kirkcaldy, Shephard, \& Siefen, 2002).

Despite these positive impacts, some negative effects have been cited. Of particular concern is increased risk-taking behavior evidenced by athletes. Although athletes are more likely to wear seatbelts, maintain higher overall levels of physical activity, demonstrate less hopelessness, and exhibit healthier dietary behaviors than their non-athlete peers, they are less likely to wear a helmet while riding a bicycle or motorcycle and are more likely to speed while driving (Baumert, Henderson, \& Thompson, 1998). Further, high school athletes report more alcohol use and a 
greater number of sexual partners than non-athletes, as well as lower perceived risk of such activities (Wetherill \& Fromme, 2007). The thrill-seeking and even reckless behavior evidenced by athletes may suggest a propensity toward risk-taking and sensation seeking. This could be a dangerous association, as research suggests that high sensation seeking, defined by Zuckerman (1979) as, "the need for varied, novel, and complex sensations and experiences and the willingness to take physical and social risks for the sake of such experiences" (p. 10), is related to an overall propensity for risk-taking, including engaging in increased and risky sexual behavior (Greene, Krcmar, Walters, Rubin, \& Hale, 2000).

Researchers are increasingly exploring the relationship between athletic participation and adolescent sexual behavior, with mixed results. Smith and Caldwell (1994) found that $60.6 \%$ of high school sport participants reported experiencing sexual intercourse, compared to only $41.8 \%$ of nonparticipants. Conversely, results from the Women's Sports Foundation Report: Sport and Teen Pregnancy (Sabo, et al., 1998) suggested that female athletes had fewer partners and less sexual experience than female non-athletes, while results were inconclusive for males.

Further complicating the relationship between sport participation and sexual activity is the possible influence of various sport-related factors that affect the overall experience of being an athlete. For example, distinctions have been made between athletes participating in sports with different levels of contact (Nixon, 1997) and team vs. individual sports (Rudd \& Stoll, 2004). In addition to these sport characteristics, factors related to athlete status might affect the sport participation experience. Athletic identity is a mediating factor in the relationship between sport participation and adolescent adjustment (Guest \& Schneider, 2003; Ryska, 2002). Though adolescent sexual behavior has not yet been examined in relation to these sport or athlete status factors, it is possible that differences in the sport experience related to these factors may impact the relationship between athletic participation and sexual activity.

Overall, the relationship between athletic participation and sexual activity remains unclear. Thus, the purpose of this exploratory study was to further examine this link. An ecological perspective, in which important factors from various parts of individuals' lives were considered, was used in order to elucidate the unique variables affecting athletes and non-athletes as they make sexual decisions. A broad measure of sexual activity, taking into account the frequency of engaging in a spectrum of behaviors, was used in response to increasing reports of the danger of ignoring sexual activity other than intercourse (Houston, Fang, Husman, \& Peralta, 2007; Schuster, Bell, \& Kanouse, 1996).

\section{Background to the Study}

\section{An Ecological Model of Sexual Activity}

In an attempt to understand why some teens are sexually active and others are not, Small and Luster (1994) proposed an ecological, risk-factor model based on the work of Urie Bronfenbrenner. (Bronfenbrenner, 2000; Bronfenbrenner \& Morris, 1998) advocated for a view of child development that strongly emphasized the role of social contexts. He proposed that variables within and among five environmental systems interact to impact development. The microsystem is the setting in which an individual lives and includes the person's family, peers, school, and neighborhood. The mesosystem refers to relations between microsystems, or connections between contexts. The exosystem is involved when experiences in a remote social setting in which the adolescent does not have an active role influences another more immediate context. The macrosystem encompasses the culture (norms of behavior, beliefs, and all other 
products of a group that are passed on from one generation to the next) in which adolescents live. The chronosystem "...involves the patterning of environmental events and transitions over the life course and sociohistorical circumstances" (Santrock, 2001, p. 49).

Likewise, Small and Luster's model proposes that risks encountered by adolescents can be grouped into distinct categories representing different parts of the adolescent's social ecology:

a) personal factors, such as intellectual ability;

b) familial factors, such as socioeconomic status;

c) extrafamilial factors, such as school attachment; and

d) macrosystems, such as media influence.

The authors supported their model with the identification of risk factors at the individual, familial, and extrafamilial levels for both males and females. Further studies have corroborated the model by demonstrating its efficacy for multiple ethnic groups and various indicators of sexual activity (Mandara, Murray, \& Bangi, 2003; Perkins, Luster, Villarruel, \& Small, 1998). To closely account for the full range of experiences adolescents face and to fully reflect the growing research base, this study included both risk and protective factors at the individual, familial, and extrafamilial levels most often associated with sexual activity in the adolescence/emerging adulthood literature.

\section{Individual Level}

Numerous studies suggest that males initiate sex at a significantly younger age, are affected by different risk and protective factors, and think about sex in different ways than do females (Little \& Rankin, 2001; Meschke, Zweig, Barber, \& Eccles, 2000; Michels, Kropp, Eyre, \& Halpern-Felsher, 2005; Miller, Sabo, Farrell, Barnes, \& Melnick, 1998). Individual personality impacts sexual decision-making, with higher levels of Extraversion, Openness to Experience, and Antagonism related to increased sexual risk-taking (Miller, Lynam, Zimmerman, Logan, Leukefeld, \& Clayton, 2004). Adolescents who use substances are more likely to be sexually experienced (Cavazos-Rehg, Krauss, Spitznagel, Schootman, Cottler, \& Bierut, 2011; Dunn, Ilapogu, Taylor, Naney, Blackwell, Wilder, et al., 2008) and the likelihood of sexual risk behaviors increases with the progression from alcohol and cigarettes to marijuana, cocaine, and other illicit drugs (Lowry, Holtzman, Truman, Kann, Collins, \& Kolbe, 1994), an association that extends to sexual behaviors other than intercourse (Schuster, Bell, \& Kanouse, 1996).

Athletes and non-athletes differ in many characteristics at the individual level. Students involved in sport have been found to be more socially competent and less shy and withdrawn than noninvolved youth (McHale, Vinden, Bush, Richer, Shaw, \& Smith, 2005). Athletes also report higher self-esteem (Daniels \& Leaper, 2006) and perceived competence, including athletic competence, social competence, behavioral competence, and global self-worth (Donaldson \& Ronan, 2006). Current and longitudinal associations were found between participation in sports and higher GPA and educational expectations, as well as lower depression and both, internalizing and externalizing behaviors (Fredricks \& Eccles, 2006). Finally, while both groups experience stress, athletes and non-athletes report different kinds of stressors (Wilson \& Pritchard, 2005).

\section{Familial Level}

Family characteristics and qualities play an important part in the sexual behavior of adolescents. Increased time spent alone at home (Perkins, Luster, Villarruel, \& Small, 1998), lack of quality relationships within the family (Miller, Sabo, Farrell, Barnes, \& Melnick (1998), relaxed parental monitoring (Rodgers, 1999), and permissive parental values toward adolescent sexual behavior 
(Small \& Luster, 1994) are all associated with increased sexual activity. An individual's participation in sport may interact with family factors in various ways. Adolescents are more likely to be physically active if they have experienced consistent parental support, modeling, and shared sport-related activities (Gustafson \& Rhodes, 2006). Sport-involved youth also report higher parental and family support than their non-involved peers (Biddle, Whitehead, O'Donovan, \& Nevill, 2005). This increased support may be particularly important for female athletes, who report close relationships with their fathers based on shared activities and sportrelated closeness (Way \& Gillman, 2000). Further, any change in an adolescent's athlete status could affect his/her functioning or relationships within the family (Newmark \& Bogacki, 2005).

\section{Extrafamilial Level}

All of an individual's life experiences are affected by the larger contexts in which he or she lives. Lack of neighborhood monitoring and living in an economically distressed neighborhood are related to adolescent sexual activity (Mandara, Murray, \& Bangi, 2003; Small \& Luster, 1994). The role of peers becomes increasingly important as individuals enter adolescence and emerging adulthood. Adolescents classified as sexually inexperienced report greater association with high-achieving peers than do those who initiate sex earlier (Meschke, Zwieg, Barber, \& Eccles, 2000). Popularity is also less important to sexually inexperienced adolescents than it is to early sexual initiators. Positive school attachment and school success are associated with less overall risk behavior, including initiating sex (Gruber \& Machamer, 2000). Strong peer relationships with teammates have been found to increase motivation in student athletes (Ommundsen, Roberts, Lemyre, \& Miller, 2005), though peer pressure on sport teams may be positive or negative (Winnail, Valois, Dowda, McKeown, Saunders, \& Pate, 1997).

Many adolescents are involved in social exchanges through activities such as clubs, sports teams, or religious groups. Adolescents with strong religious values tend to have significantly lower risky sexual behavior scores than their peers (Langer, Warheit, \& McDonald, 2001). There is some evidence to suggest that college athletes are more religious than nonathletes (Storch, Kolsky, Silvestri, \& Storch, 2001). Participation in time-use protective factors, including sports, is related to lower rates of risk-taking behavior, including engaging in sexual intercourse, as well as spending more time with friends, having an adult to talk to, being more attached to school, and having better grades (Mancini \& Huebner, 2004). One positive influence on young athletes may be a supportive coach. Coach-created climates perceived to be positive and supportive have been associated with various psychosocial benefits (Ommundsen, Roberts, Lemyre, \& Miller, 2006) and athletes reporting a good relationship with their coach have shown decreased antisocial behavior (Rutten, Stams, Biesta, Schnengel, Dirks, \& Hoeksma, 2007).

The specific purposes of this study were threefold:

(1) To determine any differences in the level of sexual activity reported by non-athletes and athletes;

(2) To discover which specific variables related to the adolescent experience influence sexual activity; and

(3) To examine any differences in the adolescent experience between athletes and nonathletes.

\section{Method}

\section{Data Collection}

The sample population for this study consisted of the approximately 36,000 undergraduate students enrolled at a large Southeastern university during the spring semester 2007. The sample consisted of three large general education courses chosen for their potential 
representativeness. The three classes sampled for data collection came from two of the largest colleges within the university and represent wide variation in subject area (communications, social science, nutrition), suggesting that a broad cross-section of majors was sampled.

A total of 437 participants completed the questionnaire for this study. Very few $(n=6)$ students present in class at the time of data collection chose not to participate in the study. In all of these cases, students offered reasons for their nonparticipation that were unrelated to the study itself (e.g., I need to use this available time to study for an exam). It was, therefore, assumed that those students who chose not to complete the questionnaire were not significantly different from those who did participate. Of the completed questionnaires, 417 were used in data analysis. Ten cases were excluded because the participants reported ages out of the intended range (18-25) and ten were excluded because they indicated that their sexual debut was not voluntary.

\section{Sample}

Participants in the study sample ranged in age from 18 to 25.83 years, with a mean age of 20.46 years (SD 1.54). The racial breakdown of the sample is representative of the university as a whole, with the majority of participants included in the study sample reporting their race/ethnic origin as White (57.4\%), followed by Black (16.9\%) and Hispanic (14.2\%). The sample was predominantly female (70.7\%). This proportion of female students is higher than that of the student body, though the university does enroll more females than males. This overrepresentation did not appear to affect the results or conclusions of the study. Regarding athlete status, the sample was fairly even, with about a third of the sample (31.1\%) reporting never being athlete, another third (38.4\%) reporting that they were an athlete in high school but not currently active in sport, and the remaining third reporting that they were athletes in high school and continue to be active in collegiate or club/intramural athletics $(30.5 \%)$.

A majority of the sample (64.3\%) reported already having their sexual debut (first sexual intercourse). The mean age of sexual debut was 17.19 years, with a range of 13.00 to 24.00 years. A composite sexual activity score was created to reflect participants' spectrum of sexual behaviors. A significant difference in mean sexual activity score was found by gender $(t=2.683$, $\mathrm{p}=.008$ ), with males reporting a mean score of 27.70 and females reporting a mean score of 24.78. This pattern was also found among the athletes $(t=2.936, p=.004)$, with male athletes reporting higher sexual activity (mean score 28.48) than female athletes (mean score 24.96). There was no difference in sexual activity score by gender for non-athletes.

\section{Instrumentation}

To assess and measure the behaviors and factors shaping the sexual activity of adolescents/emerging adults, a questionnaire was developed for use in this study to address the research questions and to be easily administered in classroom setting. The instrument consisted of 70 fixed choice and open-ended items. Included were the following conceptual areas:

Athletic Participation. This section included a multiple-choice item asking participants to classify themselves as one of the following choices:

a) high school athlete who is now a formal athlete competing for the university;

b) high school athlete who is now participating in university intramural or club sports;

c) high school athlete who no longer participates in sports; or

d) high school non-athlete. 
Respondents were advised to consider themselves athletes if they participated in any sport during their high school years, even if this activity was not an organized school sport. Because this study aimed to determine the effect of athletic participation on overall sexual activity and sexual development largely takes place in adolescence, individuals who were not athletes during high school were coded as non-athletes, regardless of college athlete status. Respondents who indicated that they were not athletes during high school were asked to skip the remainder of this section. Respondents were asked which sports they participated in and were requested to indicate a primary sport if they participated in more than one sport. Each primary sport was assigned a Level of Contact code ( $1=$ Noncontact, $2=$ Contact, $3=$ Collision) following the coding system created by Silva (1983), as well as a Team vs. Individual Sport code (1 = Team, 2 = Individual). As an indicator of intensity of participation, respondents were also asked how many hours per week, on average, they participated in their sport.

Athletic Identity Measurement Scale. Participants who reported not participating in sport while in high school did not complete this section. The Athletic Identity Measurement Scale (AIMS), a seven-item scale designed to assess athletic identity, has been found to be effective for different levels of sport involvement (non-athlete, recreational athlete, competitive athlete) and has not been found to be significantly correlated with conceptually dissimilar constructs, such as social desirability, self-esteem, and self-rated sports competence (Brewer, Van Raalte, \& Linder, 1993). General statistical support for the psychometric integrity of the AIMS has been obtained (Brewer \& Cornelius, 2001). Individual items are rated on 7-point Likert-type scales $(\mathrm{SA}=7$ and $\mathrm{SD}=1)$ and then summed for an overall athletic identity score, as well as Social Identity, Exclusivity, and Negative Affectivity domain scores. For this study, the researcher added an additional item to assess perception of membership in the "popular" group in high school. Though participants answered this question in the same manner as they answered the other items, responses were considered separately and not included in the total scores.

Ecological Variables. This section asked questions about participants' social ecology and consisted of 32 items rated on a 5-point Likert-type scale $(S A=1$ and $S D=5)$ measuring variables at the individual, familial, and extrafamilial level identified in the literature review as having an impact on sexual behavior. An exploratory factor analysis conducted with data resulting from this portion of the survey led to the formation of six distinct factors, each with its own composite score. Data resulting from this survey were factor analyzed using principal axis factoring with a varimax rotation (Kim \& Mueller, 1978). Prior to selection of factor items, the following criteria were established: a factor loading of .35 or higher; at least a .10 difference between the item's loading with its factors; and interpretability. A review of the factors with eigenvalues greater than 1.0 and further analysis of scree test plots suggested that a four, five, or six factor solution would be most appropriate, as the scree test had distinct and obvious breaks at these points. Further consideration of the items included within each of these factors indicated that the six factor solution made the most theoretical and conceptual sense. Two items ( I felt like I received a good education; and My school work was very important to me) did not meet the established criteria for inclusion into any factor and were considered as individual items for analysis.

The resulting indices were: Risk Avoidance, Parental Closeness, Parental Monitoring, Connection to School and Others, Values, and Popularity. Cronbach's alpha was determined for each of the indices to establish the level of reliability (levels available from first author upon request). Though scores were well above the generally accepted cutoff of .60 for four of the six indices, two indices had alpha values of .58. Despite the borderline value, the researcher chose to keep these groups of items as indices. This decision was based on a desire to keep the number of 
variables to a manageable number for the multivariate analyses and to preserve the degrees of freedom. Additionally, this decision was supported by the fact that multiple factor analysis runs continued to group this set of statements together in this way.

Brief Sensation Seeking Scale (BSSS). The Brief Sensation Seeking Scale (BSSS) is a selfreport Likert-type scale adapted from Form V of the Sensation Seeking Scale (Zuckerman \& Link, 1968) and designed to be suitable for survey research with adolescents and young adults (Hoyle et al., 2000). The BSSS consists of 8 items, with two items representing each of the four primary dimensions of sensation seeking (Experience Seeking, Boredom Susceptibility, Thrill and Adventure Seeking, and Disinhibition). Individual items are rated on a 5-point scale ( $S A=1$ and $\mathrm{SD}=5$ ) and are summed for a total BSSS score.

Sexual Activity. For each of a series of sexual behaviors, respondents were asked to indicate on 5 -point Likert-type scale $(0=$ Never to $5=\mathrm{A}$ lot) the frequency with which they have engaged in the behavior. If they had ever engaged in the behavior, they were asked the age (year and month) at which they first engaged in the behavior. These behaviors (kissing; French kissing; touching a partner's breast or having your breast touched by a partner, touching a partner's penis or having your penis touched by a partner, touching a partner's vagina or having your vagina touched by a partner, performing oral sex, receiving oral sex, and sexual intercourse) were adapted from the sexual timetable described by Feldman, Turner, and Araujo (1999). Sexually active participants were asked if their sexual debut was consensual and were excluded if it was not. The last question in this section was an open-ended item asking participants to think about what influenced their decision to have sex or to delay sex.

For analysis purposes, the eight items measuring frequency of engaging in sexual behaviors were combined to form an index measuring overall level of sexual activity. Scores on this scale represent the many sexual choices faced by respondents throughout their lifetime. A factor analysis was conducted, following the same procedure detailed above for the ecological variables. This suggested that these items were all highly interrelated and were consistently grouped in a one factor solution, suggesting that combining these eight items into a single scale was most appropriate. Cronbach's alpha for this scale was 0.95.

Demographics. The demographics section contained items measuring gender, race, and religious affiliation presented in a multiple-choice format. An "Other" option with space to write was provided for race and religious affiliation items. Age was also reported in years and months.

\section{Data Analysis}

Four separate reduced multiple regression models (Table 1), containing only significant variables, were developed by systematically removing the least significant variable until a parsimonious and highly predictive model was achieved. The first three models (Everyone, Nonathletes, and Athletes) include all demographic variables, ecological variable indices and remaining individual statements, and the sensation seeking domain subscales. The fourth model (Athletes+) is a reduced model including all previously included variables, along with the sport participation variables (contact vs. noncontact sport; team vs. individual sport; intensity; AIMS Social Identity; AIMS Exclusivity; AIMS Negative Affectivity; and the additional AIMS statement added by the researcher, I was part of the most popular group at school). 
Table 1

Comparison of Reduce Multivariate Models on Sexual Activity

\begin{tabular}{|c|c|c|c|c|}
\hline & \multicolumn{4}{|c|}{ Standardized regression coefficients } \\
\hline & Everyone & Non-athletes & Athletes & Athletes+ \\
\hline \multicolumn{5}{|l|}{ Demographic variables } \\
\hline Age & & & $.167 * * *$ & $.157 * * *$ \\
\hline \multicolumn{5}{|l|}{ Gender (males $=1$, females $=0$ ) } \\
\hline \multicolumn{5}{|l|}{ Race/ethnic origin } \\
\hline \multicolumn{5}{|l|}{ Black } \\
\hline \multicolumn{5}{|l|}{ Hispanic } \\
\hline \multicolumn{5}{|l|}{ Other race/ethnic origin } \\
\hline \multicolumn{5}{|l|}{ Religious affiliation } \\
\hline \multicolumn{5}{|l|}{ Christian } \\
\hline \multicolumn{5}{|l|}{ Athlete status } \\
\hline Current athlete & $-.092 *$ & & & \\
\hline \multicolumn{5}{|l|}{ High school athlete } \\
\hline \multicolumn{5}{|l|}{ Ecological variables } \\
\hline Risk avoidance & $-.245 * * *$ & $-.266^{*}$ & $-.290 * * *$ & $-.224 * * *$ \\
\hline \multicolumn{5}{|l|}{ Parental closeness } \\
\hline Parental monitoring & $-.138^{* *}$ & $-.260^{*}$ & & \\
\hline Connection to school and others & $.152^{* * *}$ & $.183^{*}$ & $.116^{*}$ & \\
\hline Values & $-.118^{*}$ & & $-.204^{* * *}$ & $-.201 * * *$ \\
\hline \multicolumn{5}{|l|}{ Popularity } \\
\hline \multicolumn{5}{|l|}{ Received good education } \\
\hline \multicolumn{5}{|l|}{ Schoolwork important } \\
\hline \multicolumn{5}{|l|}{ Sensation seeking } \\
\hline Experience seeking & & $.188^{*}$ & & \\
\hline \multicolumn{5}{|l|}{ Boredom susceptibility } \\
\hline \multicolumn{5}{|l|}{ Thrill and adventure seeking } \\
\hline Disinhibition & $.268^{* * *}$ & & $.239 * * *$ & $.261^{* * *}$ \\
\hline \multicolumn{5}{|l|}{ Athletic participation } \\
\hline Contact & & & & $-.132^{*}$ \\
\hline Team/individual & & & & $-.135 *$ \\
\hline \multicolumn{5}{|l|}{ Intensity } \\
\hline AIMS social identity & & & & $-.121^{*}$ \\
\hline \multicolumn{5}{|l|}{ AIMS exclusivity } \\
\hline \multicolumn{5}{|l|}{ AIMS negative affectivity } \\
\hline Popular group & & & & $.265^{* * *}$ \\
\hline $\mathrm{R}^{2}$ adjusted & $.281^{* * *}$ & $.237 * * *$ & $.302 * * *$ & $.366^{* * *}$ \\
\hline Cases & 382 & 112 & 276 & 276 \\
\hline
\end{tabular}

* Significant at .05 level

** Significant at .01 level

***Significant at .001 level 
Overall. The first model was significant $(F=22.317, p=.000)$ and accounted for just over $28 \%$ of the variance in sexual activity score (Adj. $\mathrm{R}^{2}=.281$ ). Six variables were found to be statistically significant. Connection to School and Others and the sensation seeking domain Disinhibition were positively related to sexual activity; the higher the score on these items, the higher the sexual activity score. Risk Avoidance, Parental Monitoring, and Values were negatively related to sexual activity; the higher the score on these items, the lower the sexual activity score. Additionally, current athlete status was negatively related to sexual activity; current athletes reported lower sexual activity scores than non-athletes.

Non-athletes. The second model, including only non-athletes $(n=112)$, was significant $(F=$ $9.685, p=.000$ ) and accounted for almost $24 \%$ of the variance in sexual activity score (Adj. $\mathrm{R}^{2}$ $=.237)$. Four variables were found to be statistically significant. Risk Avoidance and Parental Monitoring were negatively related to sexual activity; as scores on these items increased, sexual activity score decreased. Connection to School and Others and the sensation seeking domain Experience Seeking were positively related to sexual activity; as scores on these items increased, so did sexual activity score.

Athletes. The third model, including only athletes $(n=276)$, was significant $(F=24.915, p=$ .000 ) and accounted for approximately $30 \%$ of the variance in sexual activity score (Adj. $R^{2}=$ .302). Five variables were found to be statistically significant. Risk Avoidance and Values were negatively related to sexual activity; those reporting higher scores on these items reported lower sexual activity scores. Connection to School and Others and sensation seeking domain Disinhibition were positively related to sexual activity; those reporting higher scores on these items also reported higher sexual activity scores. Age was also positively related to sexual activity, with older respondents reporting higher sexual activity scores.

Athletes + . The fourth model, again including only athletes $(n=276)$, was significant $(F=$ $20.947, p=.000$ ) and accounted for approximately $36 \%$ of the variance in sexual activity score (Adj. $\mathrm{R}^{2}=.366$ ). Eight variables were found to be statistically significant. Age was again positively related to sexual activity; older respondents reported higher sexual activity scores. The sensation seeking domain Disinhibition and the AIMS statement I was part of the most popular group at schoo/ were positively associated with sexual activity; as scores on these items increased, so did sexual activity score. Risk Avoidance, Values, and AIMS Social Identity were negatively associated with sexual activity; as scores on these times increased, sexual activity score decreased. Additionally, contact sport and team sport were negatively associated with sexual activity. Contact and individual sport participants reported lower sexual activity scores than their noncontact and team sport participant counterparts.

\section{Discussion}

The purpose of this study was to explore the effects of athletic participation on adolescent/ emerging adulthood sexual activity. Findings suggest that the link between athlete status and sexual behavior may not be as direct as previously suggested. Instead, it may be some particular aspect(s) of the sport participation experience that mediate this relationship, a conclusion corroborated by previous research (Dodge \& Jaccard, 2002; Lehman \& Koerner, 2004). The efficacy of the ecological model (Small \& Luster, 1994) was supported by this research, which extended this theoretical approach to include sport participation. These results helped to answer the driving research questions of the study: 
- What specific variables related to the adolescent experience influence sexual activity?

- Are there differences in the level of sexual activity reported by nonathletes and various groups of athletes? and

- Is the adolescent experience different for athletes and no-athletes?

Several factors emerged as related to sexual activity in the initial overall model, which included all respondents. This section will discuss the major findings of this study, followed by an examination of the diversity that exists in sub-populations of athletes and non-athletes.

First, substance use (risk avoidance index) was an important influence on sexual behavior, a finding corroborated by existing research (e.g, Lowry, Holtzman, Truman, Kann, Collins, \& Kolbe, 1994; Tapert, Aarons, Sedlar, \& Brown, 2001). Choosing not to smoke, drink, or use drugs might reflect an overall commitment to a healthy and responsible lifestyle and a desire to not participate in risky behaviors, which might lead an adolescent to choose not to have sex. Further, the use of alcohol impairs judgment, and can lead to riskier choices regarding sexual activity. For example, one respondent clearly acknowledges the influence of alcohol on her choices regarding sexual behavior: "Unfortunately, most of my decisions to have sex in college have been friends of mine while under the influence of alcohol. "Adolescents who avoid using alcohol eliminate their susceptibility to this type of risky sexual choice.

Second, respondents who reported higher agreement with statements reflecting religiosity (values index) reported lower sexual activity scores. Although not all studies examining religiosity and sexual behavior have found this directional association, it is often cited as a protective factor for adolescents (Crockett, Bingham, Chopak, \& Vicary, 1996; Langer, Warheit, $\&$ McDonald, 2001). Many respondents used the open-ended question to discuss their religious convictions and the influence of those beliefs on their sexual activity, or lack thereof. For example: "My faith as a Christian has led me to abstain until marriage."

Third, the current study found that respondents who felt their parents would have strongly disapproved of them having sex while in high school (values index) reported lower sexual activity scores; this finding is consistent with that of Small and Luster (1994), who reported that negative parental values toward sex were associated with a lower chance of experiencing sexual debut in high school. Adolescents who are close to and respect their parents and who value their parents' opinions likely avoid behaviors that would upset or disappoint them. Further, children and adolescents determine which values are most important in their lives based on experience and the influence of those closest to them. Thus, parents who place a high value on abstaining from or delaying sexual activity are likely to have adolescents who internalize these values and, therefore, limit their sexual experiences.

Fourth, parental monitoring (parental monitoring index) was negatively related to sexual activity score. If parents know where their adolescents are going and whom they are with, they are in a better position to intervene if necessary. Furthermore, if adolescents know that they will be expected to discuss the circumstances surrounding where they are going with their parents before they leave and when they come home, they may be less likely to make risky choices. These factors may decrease adolescents' opportunity for sexual activity and, additionally, help them to fully think through a situation before making decisions. Finally, parents who make a purposeful effort to monitor their adolescents' whereabouts and companions may be more likely to be involved in their lives in other ways as well. Having a 
parent who is a constant source of support might help adolescents and young adults engage in healthy sexual decision-making.

Fifth, participants whose close friends did not have sex or use alcohol, cigarettes, or marijuana (risk avoidance index) reported lower sexual activity. Adolescents surrounded by peers who believe that substance use and sexual activity are not appropriate in high school avoid those behaviors may internalize these beliefs and act in the same way. Likewise, an individual whose close friends do choose to have sex and drink or smoke in high school are likely to mirror these behaviors. The following response highlights the potential negative effect of having close friends who are sexually active: "All of my friends had done it very young so I thought I should too. I did it twice and realized I wasn't ready." Another possible explanation for the influence of close friends is the tendency to seek out peers with similar beliefs. Thus, adolescents who choose not to have sex or drink may be more likely to become close friends with other adolescents who share these beliefs and expectations.

Sixth, Connection to School and Others was positively related to sexual activity. This relationship may, at first glance, seem counterintuitive. Several of the ideas encapsulated within this index were shown in the literature review to be protective factors regarding sexual behavior (Douglas, 2002; Mancini and Huebner, 2004; Small and Luster, 1994; Tayler-Seehafer, 2000). Connection to School and Others, though, reflects involvement in school activities, feelings of enjoying school and having friends there, and being cared for and protected by adults at school and in the neighborhood. Respondents who report identification with these concepts were likely active participants in class, around school, and throughout the community, thus increasing their exposure to other people, particularly those with similar interests. Additionally, Miller, Lynam, Zimmerman, Logan, Leukefeld, and Clayton (2004) found that the extraversion personality characteristic was associated with increased sexual risk taking. Adolescents who are involved in their high school and connected to those around them might be more extraverted than their peers, providing opportunity and propensity toward increased sexual activity.

Finally, consistent with prior research (e.g., Donohew, Zimmerman, Cupp, Novak, Colon, \& Abell, 2000; Hoyle, Fejfar, \& Miller, 2000), results of this study reveal a relationship between sexual behavior and propensity for sensation seeking. Sexual experiences encompass many of the qualities sought after by high sensation seekers (variety, novelty, complexity, physical sensation); increased sexual activity - more partners, greater frequency, engaging in behaviors farther along the sexual behavior spectrum - will further enhance these qualities. Specifically, score on the Disinhibition subscale was positively related to sexual activity score. Previous studies have also demonstrated a link between the concept of disinhibition and sexual behavior (Arnett, 1990; Bancroft, Janssen, Carnes, Goodrich, Strong, \& Long, 2004; Bogaert \& Fisher, 1995). This content domain is reflective of a propensity for unrestrained behavior and lack of concern for what others think of one's behavior. An approach to life based on this attitude can clearly be extended to sexual behavior. If an individual does not care about societal norms for expected sexual behavior or does not practice restraint in his/her sexual behavior, it would be expected that his/her sexual activity score would be high.

Additionally, current athlete status was significantly related to sexual activity in the overall model. This was a negative relationship, revealing that current athletes reported lower sexual activity scores than non-athletes. Evidence for this relationship is consistent with prior research (e.g., Miller, Sabo, Farrell, Barnes, \& Melnick, 1998; Savage \& Holcomb, 1999; Smith \& Caldwell, 1994), but the direction extends our knowledge of this complex relationship. Those respondents who have remained active in sport may be strongly committed to their athletic 
participation; this commitment may, in turn, affect their attitude toward sexual behavior. Sexual intercourse, as well as other sexual behaviors on the spectrum, can put an individual at risk for pregnancy or contracting a sexually transmitted infection (STI), which could negatively affect an athlete's career. The lower sexual activity score among current athletes, then, might reflect the importance of sport in their lives and a resulting commitment to avoid factors that may distract from or harm their athlete status.

The overall analysis enlightened our understanding of the factors shaping behavior. To further explore this process and better address our research goals, the remaining regression models considered athletes and non-athletes separately. These models revealed that variables found to be significant in predicting sexual activity were generally quite similar between athletes and non-athletes. There were, however, some distinct differences between the two groups.

First, while parental monitoring was negatively related to sexual activity for nonathletes, it was not significant for athletes. Athletes spend much of their leisure time involved in sport and, thus, parental monitoring may not be as salient an issue. Additionally, score on the Values index was negatively related to sexual activity for athletes, but not for non-athletes. Though not expected, this finding is consistent with previous research suggesting that college athletes are more religious than non-athletes (Storch, Kolsky, Silvestri, \& Storch, 2001). Athletes as a group may generally seek social membership or be more likely to accept and conform to social norms.

Second, there was a striking distinction between athletes and non-athletes in the particular effect of sensation seeking. Although Disinhibition was not associated with sexual activity for non-athletes, a positive relationship was found for the domain of Experience Seeking. Someone with a personality that tends toward new experiences in general would probably seek out varied sexual experiences as well; such a person would likely report a high sexual activity score. It is interesting that this link was only found for the non-athletes. Perhaps athletes' participation in sport satisfies this particular domain, while non-athletes are motivated toward other experiences, such as sexual activity

What may be suggested based on the multiple regression results is that athletic participation plays a role in an individual's overall level of sexual activity by enhancing the typical adolescent experience. Rather than replacing other predictive variables, several sport participation variables were found to be significant in the reduced multiple regression model conducted for athletes and including all independent variables in addition to the remaining variables also found in the other models. The previous model, not including athletic participation variables, explained approximately $30 \%$ of the variance in sexual activity. Adding intensity, level of contact, team vs. individual sport, and athletic identity to the analysis increased the model's explanatory power to almost $37 \%$. In this final model, contact sport, team sport, and AIMS Social Identity were found to be significantly and negatively related to sexual activity, while the statement $I$ was part of the most popular group at school was positively related to sexual activity.

Respondents playing contact and team sports reported lower sexual activity scores than their noncontact and individual sport counterparts. It is not clear why these associations should exist. The opposite relationship between level of contact and sexual activity might actually be expected. Perhaps, however, contact sport players are sufficiently stimulated on the field and, therefore, do not seek out sexual activity to fill this role. One possible explanation for the relationship between increased sexual activity and individual sport is the greater likelihood that participants of these sports would be on coed teams. Swimming/diving, for example, is a popular individual sport in which there are generally both males and females on the same team. 
Being teammates with members of the opposite sex who share and understand the same sportrelated goals and interests might be the basis for some sexual relationships. In fact, several athletes in this study addressed the effect of having teammates of the opposite sex. A male swimmer had this to say: "I practice a sport that is surrounded by half-naked girls, athletic and mostly good looking, and sex isn't a big deal." A female respondent on the crew team also discussed close relationships with team members. "My crew team was co-ed and we were all very close. I dated a guy on the team and all my good friends were on the team. These people are still my good friends and I'm still dating the guy."

Athletes reporting higher Social Identity scores received lower scores on the sexual activity scale, while athletes who considered themselves to be part of the most popular group in school reported higher sexual activity. The opposing influences of the Social Identity and popular crowd membership variables suggests that although popularity may be a risk factor for athletes, strong social identification with their athlete status may actually be protective. Perhaps athletes who are strongly attached to their athlete status and who value this status as their social representation to others are careful to preserve it, thus avoiding activities that might risk their athlete standing. Those individuals, on the other hand, for whom popularity is most important may benefit from this open social environment and the social standing afforded athletes, which might allow for increased opportunity and higher levels of sexual activity. These findings may be related to the distinction between sport participation (athlete status, social identity) and identification with the jock label (self-reported membership in most popular group). In previous studies, being a jock was associated with a variety of risky behaviors, while being an athlete was a protective factor (La Greca, Prinstein, \& Fetter, 2001; Miller, Farrell, Barnes, Melnick, \& Sabo, 2005).

\section{Conclusion}

While the results of this study provide important insight into this complex relationship, further research should build from the results of this exploratory study to more clearly elucidate the context of the relationship between sport participation and sexual behavior. First, this study only explored factors at the first three levels of the ecological model. Future research should examine macrosystem factors (the media, the sexual culture of the larger society, federal or state sexual education policies) that might affect sexual behavior. Second, this was an exploratory study attempting to identify possible relationships between numerous sport participation variables and sexual activity. Narrowly focused research with specifically targeted athlete samples may provide more comprehensive results.

The results of this study provide evidence that athletes and non-athletes are two distinct groups of students. Understanding this distinction may help school officials and youth workers more effectively reach both populations, specifically in the realm of sexual behavior, as different target populations may necessitate different interventions or combinations of interventions (Schaalma, Abraham, Gillmore, \& Kok, 2004). Additionally, it is not necessary for programs aimed at decreasing adolescent sexual behavior to solely focus on sex. Instead, support is growing for the wider implementation of youth development programs (Brindis, 2006). Such programs, with an ecological perspective as their base and asset-building as their goal, should promote psychological strength (resiliency) and prosocial behaviors. The results of this study support the basis of such programs; particularly the acknowledgment that adolescents are influenced by factors at all levels of the social ecology. Further, the importance of overall healthy decision-making (i.e., avoiding substance use) and positive peer influence, factors recommended for inclusion, was highlighted in this study. 
The impact on sexual behavior of multiple variables, particularly those associated with sport participation, has now been clearly demonstrated. It is important that this information be used to enhance the positive development of, and decrease the risk factors facing, adolescents and emerging adults struggling to safely navigate the sexual world.

\section{References}

Arnett, J. (1990). Contraceptive use, sensation seeking, and adolescent egocentrism. Journal of Youth and Adolescence, 19, 171-180.

Bancroft, J., Janssen, E., Carnes, L., Goodrich, D., Strong, D., \& Long, J. (2004). Sexual activity and risk taking in young heterosexual men: The relevance of sexual arousability, mood, and sensation seeking. The Journal of Sex Research, 41, 181-192.

Baumert, P., Henderson, J., \& Thompson, N. (1998). Health risk behaviors of adolescent participants in organized sports. Journal of Adolescent Health, 22, 460-465.

Biddle, S.J.H., Whitehead, S.H., O'Donovan, T.M., \& Nevill, M.E. (2005). Correlates of participation in physical activity for adolescent girls: A systematic review of recent literature. Journal of Physical Activity \& Health, 2, 423-434.

Bogaert, A., \& Fisher, W. (1995). Predictors of university men's number of sexual partners. The Journal of Sex Research, 32, 119-130.

Boone, E., \& Leadbetter, B. (2006). Game on: Diminishing risks for depressive symptoms in early adolescence through positive involvement in team sports. Journal of Research on Adolescence, 16, 79-90.

Brewer, B., \& Cornelius, A. (2001). Norms and factorial invariance of the Athletic Identity Measurement Scale. Academic Athletic Journal, 15, 103-113.

Brewer, B., Van Raalte, J., \& Linder, D. (1993). Athletic identity: Hercules' muscles or Achilles' heel? International Journal of Sport Psychology, 24, 237-254.

Brindis, C. (2006). A public health success: Understanding policy changes related to teen sexual activity and pregnancy. American Review of Public Health, 27, 277-295.

Bronfenbrenner, U. (2000). Ecological systems theory. In A. Kazdin (Ed.), Encyclopedia of psychology. Washington DC, and New York: American Psychological Association and Oxford University Press.

Bronfenbrenner, U., \& Morris, P. (1998). The ecology of developmental processes. In W. Damon (Ed.), Handbook of child psychology ( $5^{\text {th }}$ ed., Vol. 1). New York, NY:Wiley.

Centers for Disease Control (CDC). (2005). Youth Risk Behavior Surveillance System. Youth Online: Comprehensive Results, Sexual Behaviors. Retrieved April 10, 2007 from:

http://www.cdc.gov/healthyyouth/yrbs/index.htm 
Crockett, L., Bingham, C., Chopak, J., \& Vicary, J. (1996). Timing of first sexual intercourse: The role of social control, social learning, and problem behavior. Journal of Youth and Adolescence, 25, 89-111.

Daniels, E., \& Leaper, C. (2006). A longitudinal study of sport participation, peer acceptance, and self-esteem among adolescent girls and boys. Sex Roles, 55, 875-880.

Dodge, T., \& Jaccard, J. (2002). Participation in athletics and female sexual risk behavior: The evaluation of four causal structures. Journal of Adolescent Research, 17, 42-67.

Donaldson, S.J., \& Ronan, K.R. (2006). The effects of sports participation on young adolescents' emotional wellbeing. Adolescence, 41, 369-389.

Donohew, L., Zimmerman, R., Cupp, P., Novak, S., Colon, S., \& Abell, R. (2000). Sensation seeking, impulsive decision-making, and risky sex: Implications for risk-taking and design of interventions. Personality and Individual Differences, 28, 1079-1091.

Douglas, K. (2002). The impact of schools and school programs upon adolescent sexual behavior. Journal of Sex Research, 39, 27-33.

Feldman, S., Turner, R., \& Araujo, K. (1999). Interpersonal context as an influence on sexual timetables of youths: Gender and ethnic effects. Journal of Research on Adolescence, 9, 25-52.

Fredricks, J.A., \& Eccles, J.S. (2006). Is extracurricular participation associated with beneficial outcomes? Developmental Psychology, 42, 698-713.

Greene, K., Krcmar, M., Walters, L., Rubin, D., \& Hale, J. (2000). Targeting adolescent risktaking behaviors: The contributions of egocentrism and sensation seeking. Journal of Adolescence, 23, 439-461.

Gruber, E., \& Machamer, A. (2000). Risk of school failure as an early indicator of other health risk behaviour in American high school students. Health, Risk \& Society, 2, 59-68.

Guest, A., \& Schneider, B. (2003). Adolescents' extracurricular participation in context: The mediating effects of schools, communities, and identity. Sociology of Education, 76, 89-109.

Gustafson, S.L., \& Rhodes, R.E. (2006). Parental correlates of physical activity in children and early adolescents. Sports Medicine, 36, 79-97.

Hawkins, R., \& Mulkey, L.M. (2005). Athletic investment and academic resilience in a national sample of African American females and males in the middle grades. Education \& Urban Society, 38, 62-88.

Houston, A., Fang, J., Husman, C., \& Peralta, L. (2007). More than just vaginal intercourse: Anal intercourse and condom use patterns in the context of "main" and "casual" sexual relationships among urban minority adolescent females. Journal of Pediatric \& Adolescent Gynecology, 20, 299-304.

Hoyle, R., Fejfar, M., \& Miller, J. (2000). Personality and sexual risk taking: A quantitative review. Journal of Personality, 68, 1203-1231. 
Judgment Inventory. Sport Journal, 7. Retrieved April 10, 2007, from http://www.thesportjournal.org/2004Journal/Vol7-No2/RuddStoll.asp

Kim, J., \& Mueller, C. (1978). Factor Analysis: Statistical Methods and Practical Issues. Beverly Hills, CA: Sage Publications.

Kirkcaldy, B., Shephard, R., Siefen, R. (2002). The relationship between physical activity and self-image and problem behaviour among adolescents. Social Psychiatry and Psychiatric Epidemiology, 37, 544-550.

La Greca, A., Prinstein, M., \& Fetter, M. (2001). Adolescent peer crowd affiliation: Linkages with health-risk behaviors and close friendships. Journal of Pediatric Psychology, 26, 131-143.

Langer, L., Warheit, G., \& McDonald, L. (2001). Correlates and predictors of risky sexual practices among a multi-racial/ethnic sample of university students. Social Behavior and Personality, 29, 133-144.

Lehman, S., \& Koerner, S. (2004). Adolescent women's sports involvement and sexual behavior/health: A process-level investigation. Journal of Youth and Adolescence, 33, 443-455.

Little, C., \& Rankin, A. (2001). Why do they start it? Explaining reported early-teen sexual activity. Sociological Forum, 16, 703-729.

Lowry, R., Holtzman, D., \& Truman, B., et al. (1994). Substance use and HIV-related sexual behaviors among U.S. high school students: Are they related? American Journal of Public Health, 84, $1116-1120$.

Mancini, J. \& Huebner, A. (2004). Adolescent risk behavior patterns: Effects of structured timeuse, interpersonal connections, self-system characteristics, and socio-demographic influences. Child and Adolescent Social Work, 21, 647-668.

Mandara, J., Murray, C., \& Bangi, A. (2003). Predictors of African American adolescent sexual activity: An ecological framework. Journal of Black Psychology, 29, 337-356.

McHale, J.P., Vinden, P.G., Bush, L., Richer, D., Shaw, D., \& Smith, B. (2005). Patterns of personal and social adjustment among sport-involved and noninvolved urban middle-school children. Sociology of Sport Journal, 22, 119-137.

Meschke, L., Zweig, J., Barber, B., \& Eccles, J. (2000). Demographic, biological, psychological, and social predictors of the timing of first intercourse. Journal of Research on Adolescence, 10, 315-338.

Michels, T., Kropp, R., Eyre, S., \& Halpern-Felsher, B. (2005). Initiating sexual experiences: How do young adolescents make decisions regarding early sexual activity? Journal of Research on Adolescence, 15, 583-607.

Miller, J., Lynam, D., Zimmerman, R., Logan, T., Leukefeld, C., \& Clayton, R. (2004). The utility of the Five Factor Model in understanding risky sexual behavior. Personality and Individual Differences, 36, 1611-1626. 
Miller, K., Farrell, M., Barnes, G., Melnick, M., \& Sabo, D. (2005). Gender/racial differences in jock identity, dating, and adolescent sexual risk. Journal of Youth and Adolescence, 34, 123136.

Miller, K., Sabo, D., Farrell, M., Barnes, G., \& Melnick, M. (1998). Athletic participation and sexual behavior in adolescents: The different worlds of boys and girls. Journal of Health and Social Behavior, 39, 108-123.

Newmark, T.S., \& Bogacki, D.F. (2005). The impact of injury in the adolescent athlete and the family. Directions in Psychiatry, 25, 91-99.

Nixon, H. (1997). Gender, sport, and aggressive behavior outside sport. Journal of Sport and Social Issues, 21, 379-391.

Ommundsen, Y., Roberts, G.C., Lemyre, P., \& Miller, B.W. (2005). Peer relationships in adolescent competitive soccer: Associations to perceived motivational climate, achievement goals, and perfectionism. Journal of Sport Sciences, 23, 977-989.

Ommundsen, Y., Roberts, G.C., Lemyre, P., \& Miller, B.W. (2006). Parental and coach support or pressure on psychosocial outcomes of pediatric athletes in soccer. Clinical Journal of Sport Medicine, 16, 522-526.

Perkins, D., Luster, T., Villarruel, F., \& Small, S. (1998). An ecological, risk-factor examination of adolescents' sexual activity in three ethnic groups. Journal of Marriage and the Family, 60, 660673.

Rodgers, K. (1999). Parenting processes related to sexual risk-taking behaviors of adolescent males and females. Journal of Marriage and the Family, 61, 99-109.

Rudd, A., \& Stoll, S. (2004). What type of character do athletes possess? An empirical examination of college athletes versus college nonathletes with the RSBH Value. The Sport Journal, ISSN: 1543-9518.

Rutten, E.A., Stams, G.J.J.M., Biesta, G.J.J., Schhengel, C., Dirks, E., \& Hoeksma, J.B. (2007). The contribution of organized youth sport to antisocial and prosocial behavior in adolescent athletes. Journal of Youth and Adolescence, 36, 255-264.

Ryska, T. (2002). The effects of athletic identity and motivation goals on global competence perceptions of student-athletes. Child Study Journal, 32, 109-130.

Sabo, D., Miller, K., Farrell, M., Barnes, G., \& Melnick, M. (1998). Women's sports foundation report: Sport and teen pregnancy. East Meadow, NY: Women's Sports Foundation.

Santrock, J. (2001). Adolescence (5 $5^{\text {th }}$ ed.). New York, NY: McGraw-Hill.

Savage, M., \& Holcomb, D. (1999). Adolescent female athlete's sexual risk-taking behaviors. Journal of Youth and Adolescence, 28, 595-603. 
Schaalma, H., Abraham, C., Gillmore, M., \& Kok, G. (2004). Sex education as health promotion: What does it take? Archives of Sexual Behavior, 33, 259-269.

Schuster, M.A., Bell, R.M., \& Kanouse, D.E. (1996). The sexual practices of adolescent virgins: Genital sexual activities of high school students who have never had intercourse. American Journal of Public Health, 86, 1570-1576.

Silva, J. (1983). The perceived legitimacy of rule violating behavior in sport. Journal of Sport Psychology, 5, 438-448.

Small, S., \& Luster, T. (1994). Adolescent sexual activity: An ecological, risk-factor approach. Journal of Marriage and the Family, 56, 181-192.

Smith, E., \& Caldwell, L. (1994). Participation in high school sports and adolescent sexual activity. Pediatric Exercise Science, 6, 69-74.

Storch, E., Kolsky, A., Silvestri, S., \& Storch, J. (2001). Religiosity of elite college athletes. Sport Psychologist, 15, 346-351.

Taylor-Seehafer, M., \& Rew, L. (2000). Risky sexual behavior among adolescent women. Journal for Specialists in Pediatric Nursing, 5(1), 15-25.

Tapert, S., Aarons, G., Sedlar, G., \& Brown, S. (2001). Adolescent substance use and sexual risk-taking behavior. Journal of Adolescent Health, 28, 181-189.

Way, N., \& Gillman, D.A. (2000). Early adolescent girls' perceptions of their relationships with their fathers: A qualitative investigation. Journal of Early Adolescence, 20, 309-332.

Wetherill, R., \& Fromme, K. (2007). Alcohol use, sexual activity, and perceived risk in high school athletes and non-athletes. Journal of Adolescent Health, 41, 294-301.

Wilson, G., \& Pritchard, M. (2005). Comparing sources of stress in college student athletes and nonathletes. Athletic Insight: Online Journal of Sport Psychology, 7, no pagination specified.

Winnail, S.D., Valois, R.F., Dowda, M., McKeown, R.E., Saunders, R.P., \& Pate, R.R. (1997). Athletics and substance use among public high school students in a southern state. American Journal of Health Studies, 13, 187-195.

Zuckerman, M. (1979). Sensation seeking: Beyond the optimal level of arousal. Hillsdale, NJ: Erlbaum.

Zuckerman, M., \& Link, K. (1968). Construct validity for the sensation seeking scale. Journal of Consulting and Clinical Psychology, 32, 420-426.

(C) Copyright of Journal of Youth Development $\sim$ Bridging Research and Practice. Content may not be copied or emailed to multiple sites or posted to a listserv without copyright holder's express written permission. However, users may print, download or email articles for individual use. 